\title{
ViRTual 2D Positioning System By Using WIRELESS SENSORS IN INDOOR ENVIRONMENT
}

\author{
Hakan Koyuncu ${ }^{1}$ and Shuang Hua Yang $^{2}$ \\ ${ }^{1}$ Computer Science Department, Loughborough University, Loughborough, UK \\ 2 Computer Science Department, Loughborough University, Loughborough ,UK
}

\begin{abstract}
A $2 D$ location detection system is constructed by using Wireless Sensor Nodes (WSN) to create aVirtual Fingerprint map, specifically designed for use in an indoor environment. WSN technologies and programmable ZigBee wireless network protocols are employed. This system is based on radio-location fingerprinting technique. Both Linear taper functions and exponential taper functions are utilized with the received signal strength distributions between the fingerprint nodes to generate virtual fingerprint maps. Thus, areal and virtual combined fingerprint map is generated across the test area. K-nearest neighborhood algorithm has been implemented on virtual fingerprint maps, in conjunction with weight functions used to find the coordinates of the unknown objects. The system Localization accuracies of less than a grid space areproved in calculations.
\end{abstract}

\section{KEYWORDS}

Wireless Sensors Node (WSN), Received Signal Strength (RSS), Link Quality Indicator,(LQI), Application Program (AP), Weight function, Fingerprint, $k-N N$ algorithm, Interpolation function, Virtual Node (VN), ZigBee protocol, Jennic.

\section{INTRODUCTION}

Wireless Sensor Network technology is used for variety of indoor navigation and position detection, [1]. There are many position identification systems using optical [2,3], ultrasonic [4,5] and RF wireless technologies [6,7]. Each technology has its own characteristics and cost factors. Environmental conditions affect the accuracy of object position detection in different ways with these techniques. RF wireless technology has advantages such as having contactless and none line-of-sight nature and being able to operate in extreme environmental conditions, [8].

In RF based localization which is used in this study, the target object carries a Wireless Sensor acting as a receiver. Radio Signal Strength (RSS) information arrives at the receiver in the form of Link Quality Indicator(LQI) from nearby Wireless Sensors acting as transmitters. This information is transferred to a PC server to calculate the position of the target object. WSN localization uses fingerprint database which is constructed by the measured LQI values. Fingerprint based localization has two operational phases identified as, "off-line" and "on-line" phases. In the off-line phase, the location fingerprint database is organized.

The received LQI values fromthe transmitters via a receiver positioned at each grid point are identified as the location fingerprint of that particular grid point. In the on-line phase, LQI values, arriving from the transmitters, are received by a receiver on the target object at the unknown location. These LQI values are identified as the object fingerprint. Although the Fingerprint 
model and its database work well with many localization systems, due to its coarse nature and the relatively large distances between its grid points, RF signal receptions at grid points are affected. Each grid point is an RF signal measurement point. Random nature of the RF signal measurements at these points based on enviromental factors alsohas impact on the recordings of the uniform RSS or LQI values and correlation between these measurements are decreased.

A solution is proposed to quantize the signal strengths between the grid points and introduce a fingerprint database with denser measurement values which would reduce the signal strength uncertainties between the grid points. The number of grid points across the test area can be increased in two ways. First approach is to increase the grid points by physicallyincreasing the number of measurement points. This increase results not only in a larger fingerprint database, but in return, takes more time and effort during measurements.

Second approach, on the other hand, keeps the number of grid points the same and introduces virtual grid points between the physical grid points. Hence new LQI measurements are generated virtually and a new, larger fingerprint database is developed with real and virtual LQI measurements across the test area. The new approachdoes not utilize additional transmitters, receivers and grid measurement points. The system deploys only virtual grid points integrated among the physical grid points with a larger number of LQI values across the test area in indoor environments, $[9,10]$.

The rest of this paper is organized as follows: In section 2, a brief overview of fingerprint localization is described. In this section, Euclidian distance calculations and weight functions are introduced between the target object and the virtual grid points. In section 3, Virtual grid generation is described. In this section, virtual LQI calculations are presented with respect to linear and exponential taper functions. In section 4, implementation of this new approach is explained and the results are shown for different fingerprint databases. Finally, in section 5, discussions and conclusions aresummarized.

\section{FINGERPRINT LOCALIZATION}

In Fingerprintlocalization technique, A number of wirelesssensor transmitters and a receiver on the object are employed across the test area as shown in Figure $1 . B_{i}$ transmitters where $i=1,2,3,4$ at known positions transmit their LQI values to receiver. LQI measurements are collectedby a receiverlocatedat every measurement point identified as a grid point. These measurements are recorded in Fingerprint database.

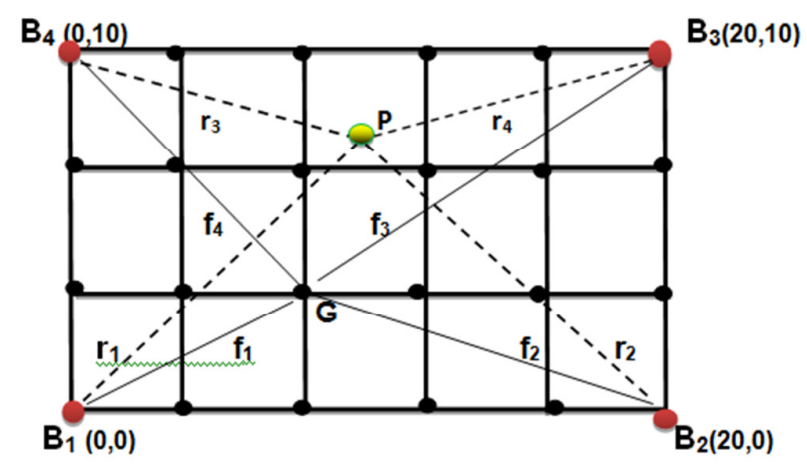

Figure 1: Grid area is showing a grid point $G$, an unknown point $P$ and $B_{i}$ transmitters where $i=1,2,3,4$ The signal distance between the object location $\mathrm{P}$ and the grid point $\mathrm{G}$ in the fingerprint map is calculated by using LQI values recorded at the respective positions. Fingerprint vector $\mathrm{F}$ is 
identified as the total LQI values from $B_{i}$ transmitters at a particular grid location $G$. The vector $F$ is denoted as

$F=\left(f_{1}, f_{2}, f_{3}, f_{4}\right)$

The unknown object location fingerprint vector $\mathrm{R}$ is the LQI values recorded at point $\mathrm{P}$ and denoted as

$\mathrm{R}=\left(\mathrm{r}_{1}, \mathrm{r}_{2}, \mathrm{r}_{3}, \mathrm{r}_{4}\right)$

Fingerprint database is prepared by collecting $\mathrm{F}$ vectors from all the grid points during off-line phase. $\mathrm{R}$ fingerprint vector at point $\mathrm{P}$ is also recorded and sent to $\mathrm{PC}$ during on-line phase, $[11,12]$.The Euclidean distance, $\mathrm{E}$, between $\mathrm{F}$ and $\mathrm{R}$ vectors at any grid point is given by:

$E=\left(\sum_{i=1}^{N}\left(f_{i}-r_{i}\right)^{2}\right)^{\frac{1}{2}}(1)$

whereN is the number of transmitters .k number of smallest Euclidean distances are selected from the total number of Euclidean distances and their corresponding coordinates are averaged out to give the estimated value of the object position coordinates $(\mathrm{x}, \mathrm{y})$. This estimation algorithm is called k-nearest neighborhood algorithm (k-NN).To improve the accuracy of the estimation, weight functions are employed with thek-NN algorithm. Object position coordinates (x,y), can be defined by equation 2 ,

$(x, y)=\sum_{i=1}^{k} w_{i}\left(x_{i}, y_{i}\right)$

where $x=\sum_{i=1}^{k} w_{i} \cdot x_{i}$ and $y=\sum_{i=1}^{k} w_{i} \cdot y_{i}$

$\mathrm{w}_{\mathrm{i}}$ is the weight function of the $\mathrm{i}^{\text {th }}$ neighboring grid point in k-nearest neighborhood and $\left(\mathrm{x}_{\mathrm{i}}, \mathrm{y}_{\mathrm{i}}\right)$ is the coordinates of the k-nearest neighborhood grid points. The weight function used in the study, [13], is defined as

$$
w_{i}=\frac{\frac{1}{E_{i}^{3}}}{\sum_{i=1}^{k} \frac{1}{E_{i}^{3}}}
$$

where $\mathrm{E}_{\mathrm{i}}$ is the individual Euclidean distances at k-nearest grid points.

\section{VIRTUAL FINGERPRINT}

A physical grid system is utilized for indoor localization where LQI measurements are carried out at each grid point and these LQI values with respect to their grid coordinates are defined as physical fingerprint. These grids are organized across the test area with ample distances between them where RF radiation shows characteristics of signal variations. In order to include these effects in localization calculations either several new LQI measurements are taken or a virtual RF signal distribution is assumed between adjacent grid points. 
Virtual RF signal strentgh values areassumed at virtual grid points between adjacent grid points following a distribution function. These virtual LQI values with respect to their coordinates are identified as virtual fingerprint. The location of virtual grid points can be defined emperically between the two adjacent grid points. A physical grid system is organized across the test area as shown in Figure 2. Transmitters are stationed at the corners with known coordinates of the test area. Grid cell size is arranged according to the size of the sensing area. Radio signals,transmittedfrom $\mathrm{B}_{1}, \mathrm{~B}_{2}, \mathrm{~B}_{3}$ and $\mathrm{B}_{4}$ transmitters, are received by the receiver on the object and at the grid points in the form of LQI values.

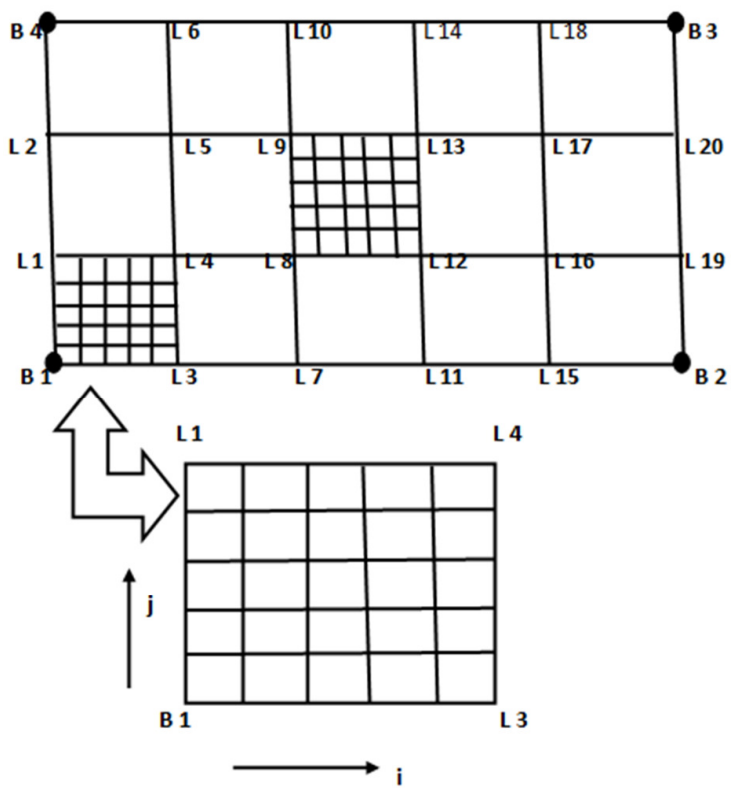

Figure 2.Physical grid space andvirtual grid cells(ie. 5) across each physical grid cell are displayed

Each physical grid cell such as $\left(\mathrm{L}_{8} \mathrm{~L}_{12} \mathrm{~L}_{13} \mathrm{~L}_{9}\right)$ is in square shape and is surrounded by 4 grid points. Each cell is further divided into $\mathbf{n}^{2}$ square shaped virtual grid cells. $\mathbf{n}-\mathbf{1}$ virtual grid points between two adjacent grid pointsaredeployed.The number of physical grid points is decided according to the size and shape of indoors. For representation purposes, the number of virtual grid cells, selected in this study, is $n=5$.

Since the coordinates of the physical grid points are defined with respect to transmitter positions, the coordinates of the virtual grid points can also be easily calculated. LQI values at adjacent grid points are considered to generate LQI values at virtual grid points between them. The distribution of virtual LQI values between two adjacent grid points are organized according to window functions named as taper functions. Once the LQI measurements arerecorded at the physical grid points, the distribution of virtual LQI values between two adjacent grid points can be assumed according to any distribution function.

Two taper functions are considered: linear taper function and exponential taper function. The distance between two adjacent grid points is divided into $\mathbf{n}$ sections. $\mathbf{n - 1}$ number of virtual LQI values aregenerated between these two adjacent grid points according to taper functions. Hence the physical grid space is divided into a finer virtual grid space. Virtual LQI values at virtual grid points and the measured LQI values at grid points produce a new fingerprint database. This fingerprint database is identified as virtual fingerprint database. 
Unknown location detection is carried out by using newly generated virtual fingerprint database and k-NN and weightedk-NN algorithms. Virtual euclidean distances areutilized betweenthe object location and the virtual grid points. $\mathrm{k}$ number of minimum virtual euclidean distances are selected and their weighted coordinates are averaged out to determine the object location. In conclusion, the positioning technique employed with virtual grid system is same as physical grid system. An overview of the proposed system is presented in a block diagram as shown in Figure 3:

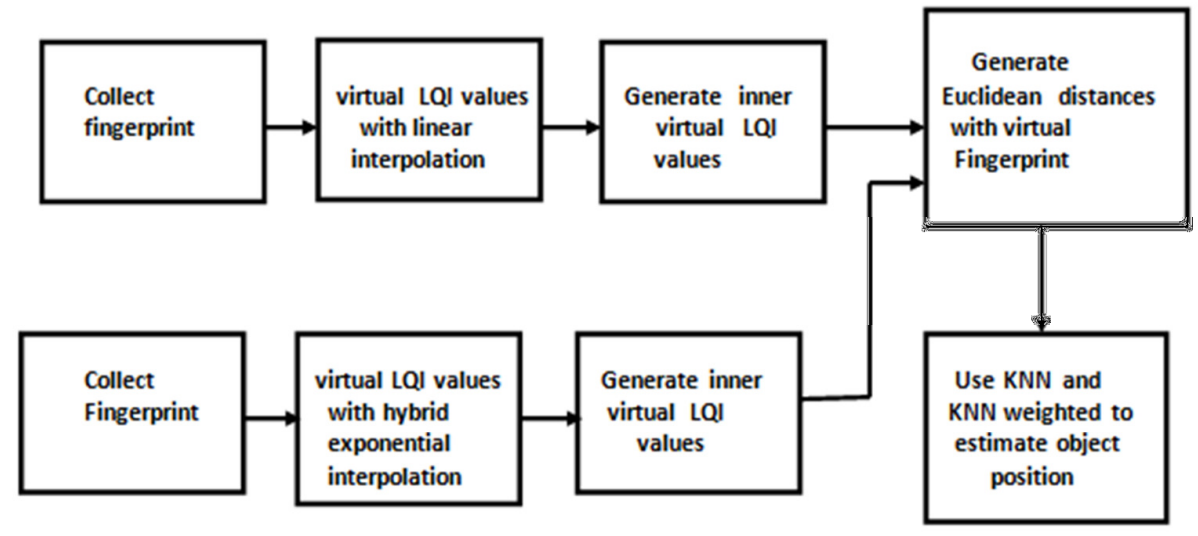

Figure 3. Block diagram of the proposed localization system

It was important that no additional wireless sensor nodes are employed across the test area. The technique introducesan increased number ofLQI values due to denser virtual grid points without any extra effort. Hence, fixed number of grid points and the fixed number of LQI data in the fingerprint database are abandoned in favor of larger number of virtual grid points and virtual LQI data.

\subsection{Linear Interpolation Function}

The proposed approach uses linear taper function which can be identified as the linear interpolation function of LQI values at virtual grid points between two adjacent physical grid points. Linear taper function is utilized to calculate the virtual LQI values in every virtual grid point.

Each physical grid cell has 4 LQI values at each grid point received from 4 transmitter. For example, LQI values received from 4 transmitters at $\mathrm{L}_{3}$ grid point of grid cell $\mathrm{B}_{1} \mathrm{~L}_{3} \mathrm{~L}_{4} \mathrm{~L}_{1}$ are defined as $L Q I_{(5,0)}^{B 1}, L Q I_{(5,0)}^{B 2}, L Q I_{(5,0)}^{B 3}, L Q I_{(5,0)}^{B 4}$. Hence, $L Q I_{(0,0)}^{k}, L Q I_{(5,0)}^{k}, L Q I_{(5,5)}^{k}$ and $L Q I_{(0,5)}^{k}$ identify the LQI values at 4 corners of the grid cell $\mathrm{B}_{1} \mathrm{~L}_{3} \mathrm{~L}_{4} \mathrm{~L}_{1}$ with respect to transmitters. Transmitters are defined as the additional $\mathrm{k}$ subscripts with LQI values at grid cell corners where $\mathrm{k}=\left\{\mathrm{B}_{1}, \mathrm{~B}_{2}, \mathrm{~B}_{3}, \mathrm{~B}_{4}\right\}$.

For $\mathrm{B}_{1} \mathrm{~L}_{3}$ horizontal boundary of the grid cell, LQI values at virtual grid points can be interpolated in terms of LQI values at $B_{1}$ and $L_{3}$ grid points as:

$$
L Q I_{(i, 0)}^{k}=L Q I \underset{(0,0)}{k}+\frac{L Q I \stackrel{k}{k}-L Q I_{(0,0)}^{k}}{5} . i
$$


International Journal of Wireless \& Mobile Networks (IJWMN) Vol. 5, No. 6, December 2013

$L Q I_{(i, 0)}^{k}$ defines the $\mathrm{LQI}$ value at $\mathrm{i}^{\text {th }}$ virtual grid point along $\mathrm{X}$ axis with respect to $\mathrm{k}^{\text {th }}$ transmitter. Virtual LQI values along $\mathrm{B}_{1} \mathrm{~L}_{3}$ can be defined for $\mathrm{B}_{1}$ transmitter by substituting $\mathrm{k}=\mathrm{B}_{1}$ and varyingi between 0 and 5 in equation 4 . See Table 1 .

Table 1. LQI values at real and virtual grid points along $B_{1} L_{3}$ of $B_{1} L_{3} L_{4} L_{1}$ grid cell for $B_{1}$ transmitter

\begin{tabular}{|c|c|c|c|}
\hline $\begin{array}{c}\text { Grid } \\
\text { number (i) }\end{array}$ & LQI index & LQI values & Grid types \\
\hline $\mathbf{0}$ & $L Q I \begin{array}{l}B 1 \\
(0,0)\end{array}$ & $\begin{array}{ll}L Q I & \begin{array}{l}B 1 \\
(0,0)\end{array}\end{array}$ & $B_{1}$ real grid point \\
\hline 1 & $L Q I \begin{array}{l}B 1 \\
(1,0)\end{array}$ & $\frac{4}{5} L Q I \underset{(0,0)}{B 1}+\frac{1}{5} L Q I \underset{(5,0)}{B 1}$ & Virtual grid point \\
\hline 2 & $L Q I \quad \begin{array}{l}B 1 \\
(2,0)\end{array}$ & $\frac{3}{5} L Q I I_{(0,0)}^{B 1}+\frac{2}{5} L Q I \underset{(5,0)}{\stackrel{B 1}{(1)}}$ & Virtual grid point \\
\hline 3 & $L Q I \begin{array}{l}B 1 \\
(3,0)\end{array}$ & $\frac{2}{5} L Q I \underset{(0,0)}{B 1}+\frac{3}{5} L Q I_{(5,0)}^{B 1}$ & Virtual grid point \\
\hline 4 & $L Q I \quad \begin{array}{l}B 1 \\
(4,0)\end{array}$ & $\frac{1}{5} L Q I I_{(0,0)}^{B 1}+\frac{4}{5} L Q I \underset{(5,0)}{B 1}$ & Virtual grid point \\
\hline 5 & $L Q I \begin{array}{c}B 1 \\
(5,0)\end{array}$ & $L Q I \begin{array}{l}B 1 \\
(5,0)\end{array}$ & $\mathrm{L}_{3}$ real grid point \\
\hline
\end{tabular}

By varying $\mathrm{k}$ values, virtual LQI values with respect to other transmitters can also be determined along $\mathrm{B}_{1} \mathrm{~L}_{3}$ boundary. Hence, there are 4 virtual LQI values for 4 transmitters for each $\mathrm{i}$ along $B_{1} L_{3}$. SimilarlyFor $B_{1} L_{1}$ vertical boundary of the same grid cell, $L Q I$ values at the virtual grid points can be interpolated in terms of LQI values at $\mathrm{B}_{1}$ and $\mathrm{L}_{1}$ grid points as:

$L Q I_{(0, j)}^{k}=L Q I_{(0,0)}^{k}+\frac{L Q I_{(0,5)}^{k}-L Q I_{(0,0)}^{k}}{5} \cdot j$

$\mathrm{j}$ is the number of virtual grid points along $\mathrm{Y}$ axis and $\mathrm{k}$ represents transmitters. $L Q I_{(0, j)}^{k}$ defines the LQI value at $j^{\text {th }}$ virtual grid point with respect to $k^{\text {th }}$ transmitter. Virtual LQI values along $B_{1} L_{1}$ can be defined for $B_{1}$ transmitter by substituting $k=B_{1}$ and $j$ varies between 0 and 5 in equation 5. See Table 2.

Table 2. LQI values at real and virtual grid points along $B_{1} L_{1}$ of $B_{1} L_{3} L_{4} L_{1}$ grid cell for $B_{1}$ transmitter

\begin{tabular}{|c|c|c|c|}
\hline $\begin{array}{c}\text { Grid } \\
\text { number }(\mathbf{j})\end{array}$ & LQI index & LQI values & Grid types \\
\hline 0 & $L Q I \quad \begin{array}{l}B 1 \\
(0,0)\end{array}$ & $L Q I \begin{array}{l}B 1 \\
(0,0)\end{array}$ & $B_{1}$ real grid point \\
\hline 1 & $L Q I \begin{array}{l}B 1 \\
(0,1)\end{array}$ & $\frac{4}{5} L Q I_{(0,0)}^{B 1}+\frac{1}{5} L Q I_{(0,5)}^{B 1}$ & Virtual grid point \\
\hline 2 & $L Q I \quad \begin{array}{l}B 1 \\
(0,2)\end{array}$ & $\frac{3}{5} L Q I \underset{(0,0)}{\stackrel{B 1}{(0)}+\frac{2}{5} L Q I} \underset{(0,5)}{B 1}$ & Virtual grid point \\
\hline 3 & $L Q I \quad \begin{array}{l}B 1 \\
(0,3)\end{array}$ & $\frac{2}{5} L Q I \stackrel{B 1}{(0,0)}+\frac{3}{5} L Q I \stackrel{B 1}{(0,5)}$ & Virtual grid point \\
\hline 4 & $L Q I \begin{array}{l}B 1 \\
(0,4)\end{array}$ & $\frac{1}{5} L Q I \underset{(0,0)}{B 1}+\frac{4}{5} L Q I \underset{(0,5)}{B 1}$ & Virtual grid point \\
\hline 5 & $L Q I \begin{array}{l}B 1 \\
(0,5)\end{array}$ & $L Q I \begin{array}{l}B 1 \\
(0,5)\end{array}$ & $L_{3}$ real grid point \\
\hline
\end{tabular}

$\mathrm{k}$ values can be varied again and virtual LQI values with respect to other transmitters can be determined similarly along $\mathrm{B}_{1} \mathrm{~L}_{1}$ boundary. A schematical representation of linear LQI 
distributions along $B_{1} L_{3}$ and $B_{1} L_{1}$ boundaries of the grid cell $B_{1} L_{3} L_{4} L_{1}$ for transmitter $B_{1}$, is given in Figure 4.

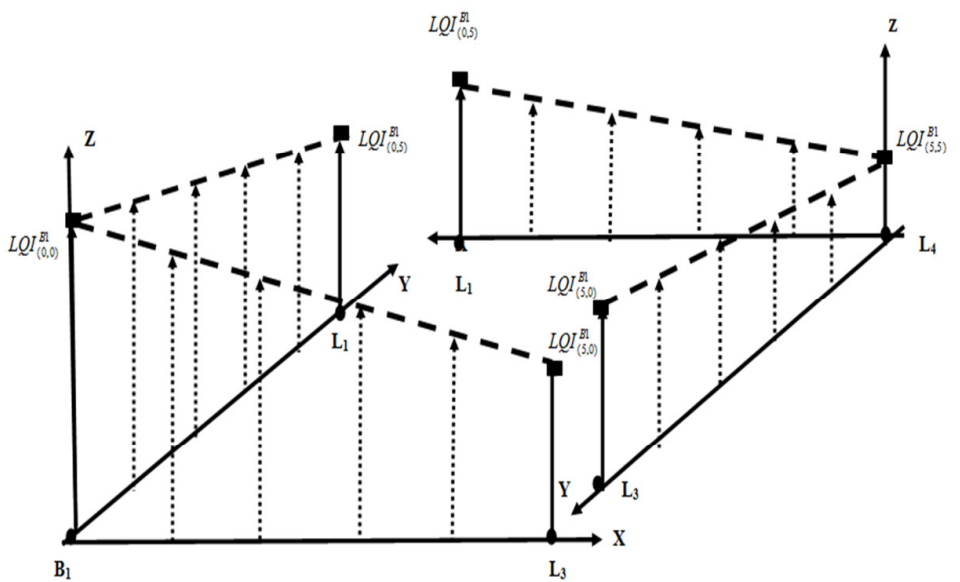

Figure 4. Linear LQI distributions are displayed along the grid cell boundaries $B_{1} L_{3}$ and $B_{1} L_{1}$ for $B_{1}$ transmitter. Each dotted arrow represents a virtual LQI value between grid points

Virtual LQI values at boundaries $\mathrm{L}_{1} \mathrm{~L}_{4}$ and $\mathrm{L}_{3} \mathrm{~L}_{4}$ of the grid cell $\mathrm{B}_{1} \mathrm{~L}_{3} \mathrm{~L}_{4} \mathrm{~L}_{1}$ can also be determined for $B_{1}$ transmitter similar to $B_{1} L_{3}$ and $B_{1} L_{1}$. Once virtual $L Q I$ values are determined for all the grid cell boundaries, virtual LQI values at virtual grid points inside the grid cell can be calculated with respect to these boundary values. For $j=1$ and i varies between 0 and 5, virtual LQI values can be determined for kth transmitter by using the following LQIboundary values.

$$
L Q I_{(0,0)}^{k}+\frac{1}{5}\left(L Q I_{(0,5)}^{k}-L Q I_{(0,0)}^{k}\right) \text { and } L Q I_{(5,0)}^{k}+\frac{1}{5}\left(\operatorname{LQI}_{(5,5)}^{k}-\operatorname{LQI}_{(5,0)}^{k}\right)
$$

Similarly, fori 1 and $\mathrm{j}$ varies between 0 and 5 , virtual LQI values can also be determined by using the following LQI boundary values.

$$
L Q I_{(0,0)}^{k}+\frac{1}{5}\left(L Q I_{(5,0)}^{k}-L Q I_{(0,0)}^{k}\right) \text { and } L Q I_{(0,5)}^{k}+\frac{1}{5}\left(L Q I_{(5,5)}^{k}-L Q I_{(0,5)}^{k}\right)
$$

These boundary LQI values can be displayed with respect to grid cell in Figure5.

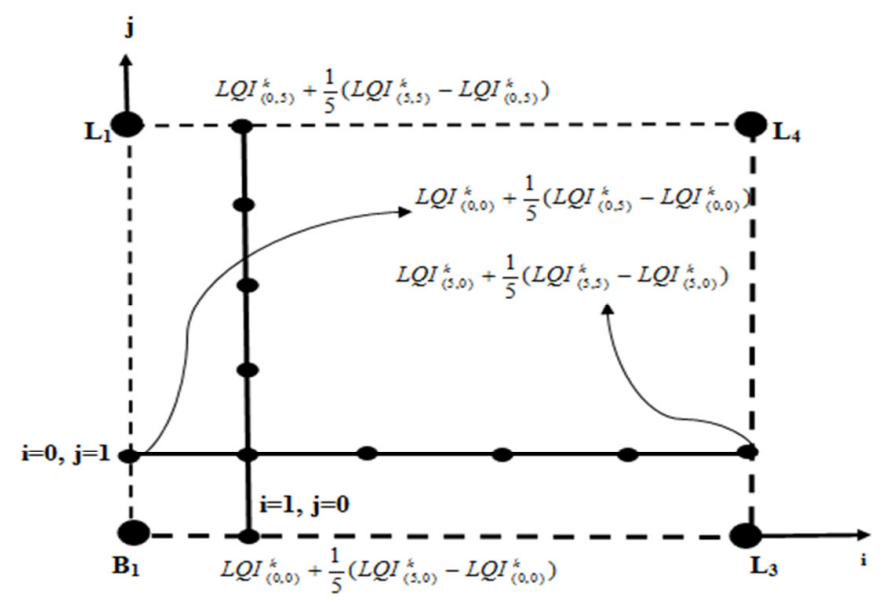

Figure 5. LQI boundary values for $\mathrm{j}=1, \mathrm{i}=0$ to 5 and $\mathrm{i}=1, \mathrm{j}=0$ to 5 for $\mathrm{k}^{\text {th }}$ transmitter are displayed

When $\mathrm{j}=1$ and $\mathrm{i}$ varies between 0 and 5 along the horizontal line parallel to $\mathrm{B}_{1} \mathrm{~L}_{3}$, virtual LQI values can be shown in Table 3 for $B_{1}$ transmitter. Similarly, when $\mathrm{i}=1$ and $\mathrm{j}$ varies between 0 
International Journal of Wireless \& Mobile Networks (IJWMN) Vol. 5, No. 6, December 2013

and 5 along the vertical line parallel to $\mathrm{B}_{1} \mathrm{~L}_{1}$, virtual LQI values can also be shown in Table 4 for $\mathrm{B}_{1}$ transmitter.

These Virtual LQI calculations will be repeated for each horizontal and vertical line along $\mathrm{i}$ and $\mathrm{j}$ directions in the grid cell. As a result, there will be 2 virtual LQI values generated for each virtual grid point $(i, j)$. Average of two virtual LQI values is taken as the final virtual LQI value at that inner virtual grid point $(\mathrm{i}, \mathrm{j})$ for $\mathrm{k}$ transmitter.

Table 3. LQI values for $\mathrm{j}=1, \mathrm{i}=0$ to 5 for $\mathrm{B}_{1}$ transmitter in $\mathrm{B}_{1} \mathrm{~L}_{3} \mathrm{~L}_{4} \mathrm{~L}_{1}$ grid cell

\begin{tabular}{|c|c|}
\hline Grid No (i,j) & LQI values(horizontal to $\left.\mathbf{B}_{\mathbf{1}} \mathbf{L}_{\mathbf{3}}\right)$ \\
\hline $\mathbf{0 , 1}$ & $\frac{4}{5} L Q I_{(0,0)}^{B 1}+\frac{1}{5} L Q I_{(0,5)}^{B 1}$ \\
\hline $\mathbf{1 , 1}$ & $\frac{16}{25} L Q I_{(0,0)}^{B 1}+\frac{4}{25} L Q I_{(0,5)}^{B 1}+\frac{4}{25} L Q I_{(5,0)}^{B 1}+\frac{1}{25} L Q I_{(5,5)}^{B 1}$ \\
\hline $\mathbf{2 , 1}$ & $\frac{12}{25} L Q I_{(0,0)}^{B 1}+\frac{3}{25} L Q I_{(0,5)}^{B 1}+\frac{8}{25} L Q I_{(5,0)}^{B 1}+\frac{2}{25} L Q I_{(5,5)}^{B 1}$ \\
\hline $\mathbf{3 , 1}$ & $\frac{8}{25} L Q I_{(0,0)}^{B 1}+\frac{2}{25} L Q I_{(0,5)}^{B 1}+\frac{12}{25} L Q I_{(5,0)}^{B 1}+\frac{3}{25} L Q I_{(5,5)}^{B 1}$ \\
\hline $\mathbf{4 , 1}$ & $\frac{4}{25} L Q I_{(0,0)}^{B 1}+\frac{1}{25} L Q I_{(0,5)}^{B 1}+\frac{16}{25} L Q I_{(5,0)}^{B 1}+\frac{4}{25} L Q I_{(5,5)}^{B 1}$ \\
\hline $\mathbf{5 , 1}$ & $\frac{4}{5} L Q I_{(5,0)}^{B 1_{(j)}}+\frac{1}{5} L Q I_{(5,5)}^{B 1}$ \\
\hline
\end{tabular}

Table 4. LQI values fori $=1, j=0$ to 5 for $B_{1}$ transmitter in $B_{1} L_{3} L_{4} L_{1}$ grid cell

\begin{tabular}{|c|c|}
\hline Grid No(i, j) & LQI values(horizontal to $B_{1} L_{4}$ ) \\
\hline 1,0 & $\frac{4}{5} L Q I_{(0,0)}^{B 1}+\frac{1}{5} L Q I_{(5,0)}^{B 1}$ \\
\hline 1,1 & $\frac{16}{25} L Q I \underset{(0,0)}{B 1}+\frac{4}{25} L Q I \underset{(5,0)}{B 1}+\frac{4}{25} L Q I_{(0,5)}^{B 1}+\frac{1}{25} L Q I \underset{(5,5)}{B 1}$ \\
\hline 1,2 & $\frac{12}{25} L Q I_{(0,0)}^{B 1}+\frac{3}{25} L Q I_{(5,0)}^{B 1}+\frac{8}{25} L Q I_{(0,5)}^{B 1}+\frac{2}{25} L Q I_{(5,5)}^{B 1}$ \\
\hline 1,3 & $\frac{8}{25} L Q I_{(0,0)}^{B 1}+\frac{2}{25} L Q I_{(5,0)}^{B 1}+\frac{12}{25} L Q I_{(0,5)}^{B 1}+\frac{3}{25} L Q I_{(5,5)}^{B 1}$ \\
\hline 1,4 & $\frac{4}{25} L Q I_{(0,0)}^{B 1}+\frac{1}{25} L Q I_{(0,5)}^{B 1}+\frac{16}{25} L Q I_{(5,0)}^{B 1}+\frac{4}{25} L Q I_{(5,5)}^{B 1}$ \\
\hline 1,5 & $\frac{4}{5} L Q I_{(0,5)}^{B 1}+\frac{1}{5} L Q I_{(5,5)}^{B 1}$ \\
\hline
\end{tabular}


International Journal of Wireless \& Mobile Networks (IJWMN) Vol. 5, No. 6, December 2013

\subsection{Hybrid Exponential Interpolation Function}

Transmitted LQI values decrease with respect to distance between the transmitter and a wireless sensor receiver. A best fit curve on the experimental LQI distribution canbe shown as exponential function in the form of $a e^{-b x}$. This is presented in implementation section.

Due to the exponential decreasing propertiesof LQIvalues between transmitters and receivers across the grid space, LQI values received at grid points are also assumed to be exponentially decreasing along the directions of transmissions at thegrid cell boundaries. These assumptions are presented schematically in Figure 6and Figure 7 for $\mathrm{B}_{1}$ transmitter along the boundaries ofB $\mathrm{B}_{1}, \mathrm{~L}_{3}, \mathrm{~L}_{4}, \mathrm{~L}_{1}$ grid cell.

Coordinates of the virtual grid points are calculated with respect to transmitter coordinates. There are $\mathrm{k}$ number of LQI values arrivingfrom ktransmitters recordedat each physical grid pointto generate virtualexponential LQI distributionsbetween 2adjacent grid points along the cell boundaries.

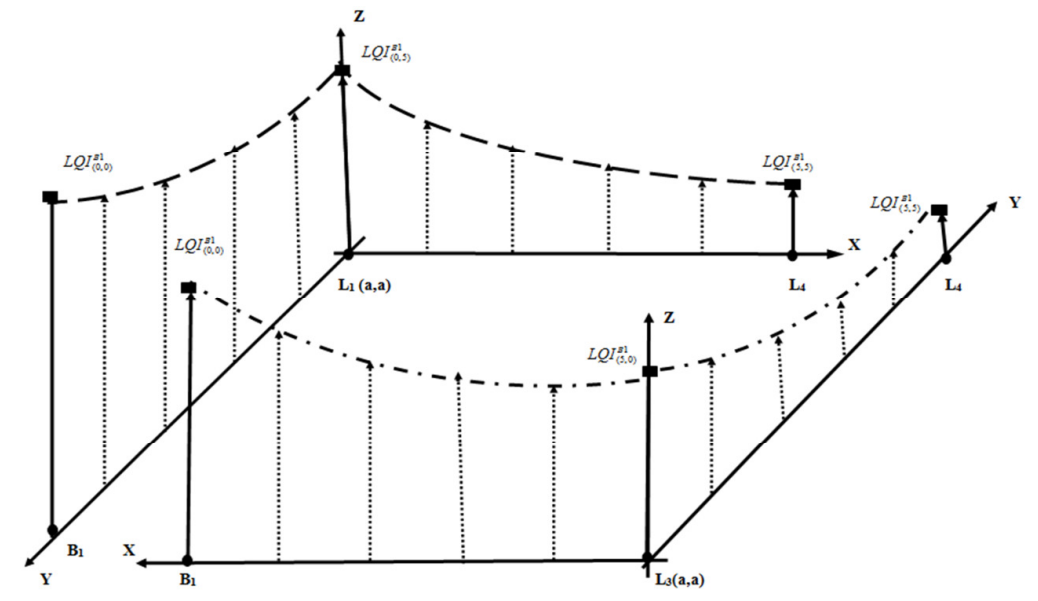

Figure 6. Schematical view of Exponential LQI interpolation functions starting from grid points a) $B_{1}$ and b) $\mathrm{L}_{4}$ along the cell boundaries for LQI transmissions of $\mathrm{B}_{1}$ transmitter

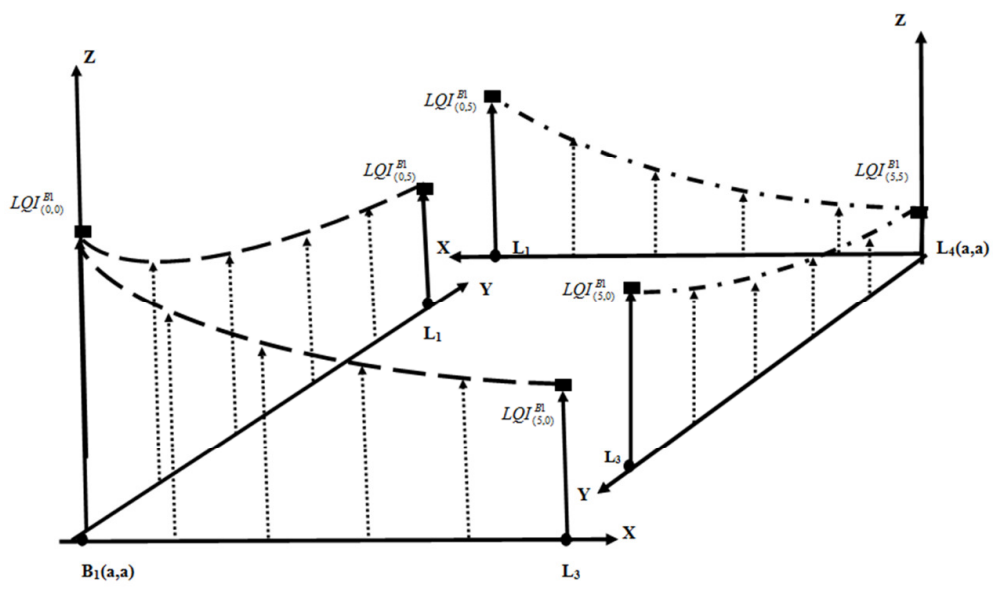

Figure 7. Schematical view of Exponential LQI interpolation functions starting from grid points a) $\mathrm{L}_{1}$ and b) $\mathrm{L}_{3}$ along the cell boundaries for LQI transmissions of $\mathrm{B}_{1}$ transmitter 
International Journal of Wireless \& Mobile Networks (IJWMN) Vol. 5, No. 6, December 2013

Grid cell $\mathrm{B}_{1} \mathrm{~L}_{3} \mathrm{~L}_{4} \mathrm{~L}_{1}$ is considered for the realization of virtual LQI values at virtual grid points as an example. LQI value received from $\mathrm{B}_{1}$ transmitter at grid point $\mathrm{B}_{1}$ is identified as $L Q I_{(0,0)}^{B 1}$ and it decreases exponentially towards $\mathrm{L}_{3}$ and $\mathrm{L}_{1}$ adjacent grid points. Similarly LQI value received from $\mathrm{B}_{2}$ transmitter at grid point $\mathrm{L}_{3}$ is identified as $L Q I_{(5,0)}^{B 2}$ and this value decreases exponentially towards $\mathrm{B}_{1}$ and $\mathrm{L}_{4}$ grid points.

The decrease of LQI values isidentified with exponential taper function between two LQI values coming from the same transmitter at 2 adjacent grid points. The taper function for LQI values,transmitted from $B_{1}$ transmitter,between $B_{1}$ and $L_{3}$ is shown in Figure 8 and expressed as;

$$
(L Q I \underset{(a, a)}{B 1}-L Q I \underset{(a+5, a)}{B 1}) e^{-(x-a)}+L Q I \underset{(a+5)}{B 1}
$$

On the other hand, the taper function for LQI values between $B_{1}$ and $L_{3}$,transmittedfrom $\mathrm{B}_{2}$ transmitter,is shownin Figure 9 andexpressed as;

$$
(L Q I \underset{(a+5,0)}{B 2}-L Q I \underset{(a, a)}{B 2}) e^{-(x-a-5)}+L Q I \underset{(a, a)}{B 2}
$$

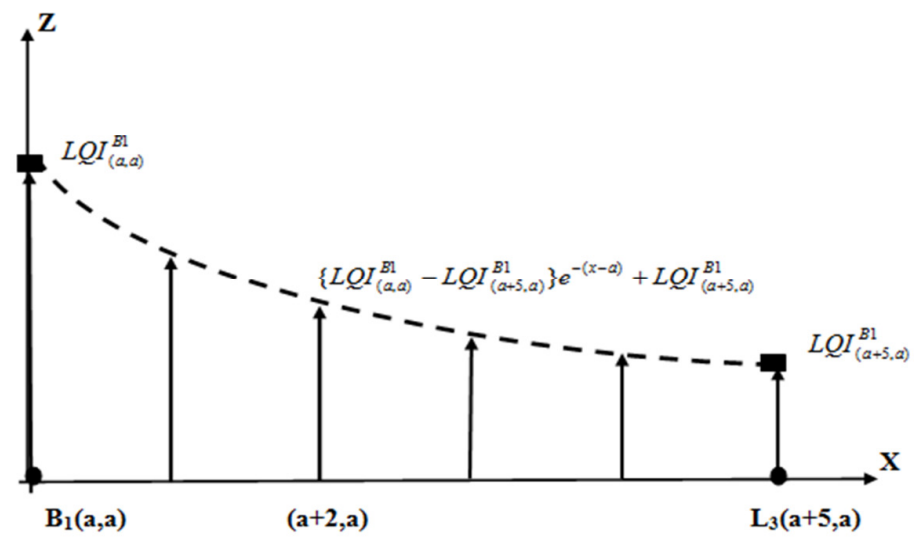

Figure 8. Graphical view of exponential taper function for grid cell boundary $\mathrm{B}_{1} \mathrm{~L}_{3}$ and 4 virtual grid

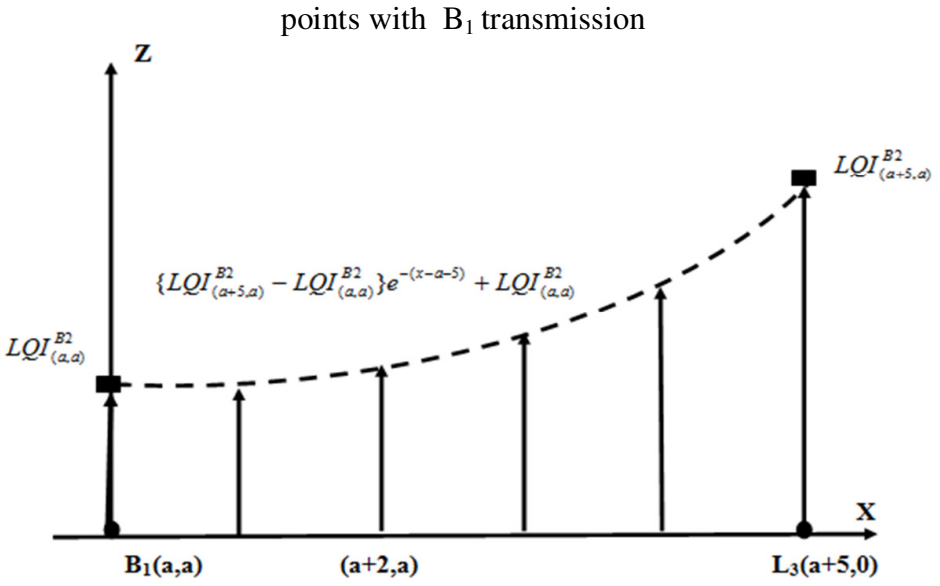

Figure 9. Graphical view of exponential taper function for grid cell boundary $B_{1} L_{3}$ and 4 virtual grid points with $\mathrm{B}_{2}$ transmission 
Virtual LQI values along $B_{1} \mathrm{~L}_{3}, \mathrm{~B}_{1} \mathrm{~L}_{1}, \mathrm{~L}_{1} \mathrm{~L}_{4}$ and $\mathrm{L}_{3} \mathrm{~L}_{4}$ boundaries can be calculated by using exponential taper functions as shown in Figure 6 and7. These virtual LQI values are tabulated in Table 5.Each grid corner $\mathrm{B}_{1}, \mathrm{~L}_{1}, \mathrm{~L}_{3}$ and $\mathrm{L}_{4}$ is considered as theRF transmission coordinatecenter $(\mathrm{a}, \mathrm{a})$ during calculations.Virtual grid points are located at incremental steps of 1along the grid boundaries with a generalcoordinate system of origin $(\mathrm{a}, \mathrm{a})$ corresponding to origin $(0,0)$.

Table 5. LQI values at real and virtual gridpoints around the grid cell boundaries for $\mathrm{B}_{1}$ transmissions

$$
\begin{gathered}
\text { where } A=\left\{L Q I_{(a, a)}^{B 1}-L Q I_{(a+5, a)}^{B 1}\right\}, B=L Q I_{(a+5, a)}^{B 1}, C=\left\{L Q I_{(a, a)}^{B 1}-L Q I_{(a, a+5)}^{B 1}\right\}, \\
D=L Q I_{(a, a+5)}^{B 1}, E=\left\{L Q I_{(a, a+5)}^{B 1}-L Q I_{(a+5, a+5)}^{B 1}\right\}, F=L Q I_{(a+5, a+5)}^{B 1}, R=L Q I_{(a+5, a+5)}^{B 1}, \\
P=\left\{L Q I_{(a+5, a)}^{B 1}-L Q I_{(a+5, a+5)}^{B 1}\right\},
\end{gathered}
$$

\begin{tabular}{|c|c|c|c|c|c|}
\hline $\begin{array}{c}\text { Grid } \\
\text { locations } \\
\text { along X }\end{array}$ & $\begin{array}{c}\text { LQI values } \\
\mathbf{B}_{\mathbf{1}} \mathbf{L}_{\mathbf{3}} \text { Boundary }\end{array}$ & $\begin{array}{c}\text { LQI values } \\
\mathbf{L}_{\mathbf{1}} \mathbf{L}_{\mathbf{4}} \text { Boundary }\end{array}$ & $\begin{array}{c}\text { Grid } \\
\text { locations } \\
\text { along } \mathbf{Y}\end{array}$ & $\begin{array}{c}\text { LQI values } \\
\mathbf{B}_{\mathbf{1}} \mathbf{L}_{\mathbf{1}} \text { Boundary }\end{array}$ & $\begin{array}{c}\text { LQI values } \\
\mathbf{L}_{\mathbf{3}} \mathbf{L}_{\mathbf{4}} \text { Boundary }\end{array}$ \\
\hline $\mathrm{a}$ & $L Q I_{(a, a)}^{B 1}$ & $L Q I_{(a, a+5)}^{B 1}$ & $\mathrm{a}$ & $L Q I_{(a, a)}^{B 1}$ & $L Q I_{(a+5, a)}^{B 1}$ \\
\hline $\mathrm{a}+1$ & $A e^{-1}+B$ & $E e^{-1}+F$ & $\mathrm{a}+1$ & $C e^{-1}+D$ & $P e^{-1}+R$ \\
\hline $\mathrm{a}+2$ & $A e^{-2}+B$ & $E e^{-2}+F$ & $\mathrm{a}+2$ & $C e^{-2}+D$ & $P e^{-2}+R$ \\
\hline $\mathrm{a}+3$ & $A e^{-3}+B$ & $E e^{-3}+F$ & $\mathrm{a}+3$ & $C e^{-3}+D$ & $P e^{-3}+R$ \\
\hline $\mathrm{a}+4$ & $A e^{-4}+B$ & $E e^{-4}+F$ & $\mathrm{a}+4$ & $C e^{-4}+D$ & $P e^{-4}+R$ \\
\hline $\mathrm{a}+5$ & $A e^{-5}+B$ & $E e^{-5}+F$ & $\mathrm{a}+5$ & $C e^{-5}+D$ & $P e^{-5}+R$ \\
\hline
\end{tabular}

Once the virtual LQI values are determined for one transmitter around the grid cell boundaries, other virtual LQI values can also be determined for other transmitters around the same boundaries. Boundary LQI values of a grid cell are utilized to calculate the internal virtual LQI values of the grid cell.

Virtual LQI values on two cell boundaries facing opposite to each other are considered and the virtual LQI values are calculated betweenthem by using linear interpolation technique. Final virtual LQI value is derived by averaging the two resultant LQI values obtained horizantal and vertical directions.

\section{IMPLEMENTATION}

JENNIC JN5139 wireless sensor nodes are deployed in the study. Zigbee Home Sensor program is used to program JN5139 active devices to work as both transmitter and receiver WSNs respectively [14]. JN5139 receiver,[15],on the object is interfaced to a computer via a wireless link for data transmission.ZigBee protocol which is based on IEEE 802.15.4 standard in $2.4 \mathrm{GHz}$ frequency band is used during the communication and data transmission between the transmitter and receiver nodes.

A rectangular area of $20 \mathrm{~m} \times 12 \mathrm{~m}$ in a sports hall is selected and unknown object locations are limited in this rectangular grid area.The area was not free of obstacles. There were sportsequipments lying around and people were doing sports and moving around during the measurements. Wireless Sensor transmitters are placed at the corners of the rectangular area.Recordings of LQI values coming from transmitters are collected by a wireless sensor receiversequentially placed at each grid point. Power consumption by the sensors during the construction of fingerprint map and computations is negligible. The wireless sensors are active devices and their onboard battery life is around 1 month. Total LQImeasurements, 
International Journal of Wireless \& Mobile Networks (IJWMN) Vol. 5, No. 6, December 2013

datacollection and recording in fingerprint database takes only 1-2 hours. Secondly, there is no onboard processor and as a result, there are no onboard computations with these sensors. Construction of the database and the localization computations take place in server computer. Hence the only energy used by the sensors is to transmit the LQI values.

For a grid area of $20 \mathrm{mx} 12 \mathrm{~m}, 24$ grid points are arranged with a grid space of 4 meters. There are 96 LQI entries recorded in the fingerprint database with 4 LQI readings at each grid point from 4 transmitters. Each entry in the database includes a mapping of the grid coordinate $(\mathrm{x}, \mathrm{y})$ and $4 \mathrm{LQI}$ values at that point.

Wireless receiver on the object receives 4 LQI values from 4 transmitters from its 4 channels and transmits them to server computer via a wireless link. There is no onboard memory at the receiver and these values are stored sequentially in an access database in a servercomputer.Server computer has sufficient memory space to manipulate these LQI values for position calculations.Received signal strengths can vary depending on the environmental effects. These variations are reduced by averaging 100recorded LQI values at each measurement pointfor each transmitter. Averaged LQI values and the position coordinates are employed to generate the fingerprint map in the server.LQI recordings of the object receiver at unknown locations are also carried outsimilarly to generate object fingerprint vectors.

\subsection{Linear Interpolation}

Each Grid cell is further divided into 5x5 virtual grid cells as an example. Therefore there are total $3 \times 5 \times 25=375$ grid cellsand $26 \times 16=416$ grid points and 416 LQI values from each transmitters across the testing area.

Initially, k-NN and weighted k-NN algorithms are utilized to determine the unknown target locations by using basic fingerprint database with 24 grid points. Results are presented in Table 6. The same localization algorithms are deployed with virtual fingerprint database generated with Linear interpolation function. Unknown object coordinates are determined and the results are presented in Table 6 .

Table 6.Estimated object position coordinates using basic fingerprint database and virtual fingerprint databases with linear and hybrid exponential interpolation functions

\begin{tabular}{|c|c|c|c|c|c|c|c|c|c|c|c|c|c|c|c|}
\hline \multirow{3}{*}{$\begin{array}{c}\begin{array}{c}\text { Unknown } \\
\text { object }\end{array} \\
\text { X y }\end{array}$} & \multicolumn{15}{|c|}{ Estimated object position coordinates using k-NN and weighted k-NN } \\
\hline & \multicolumn{3}{|c|}{ 1-NN $\mathrm{X}, \mathrm{Y}$} & \multicolumn{3}{|c|}{ 2-NN X,Y } & \multicolumn{3}{|c|}{ 3-NN $\quad X, Y$} & \multicolumn{3}{|c|}{ 4-NN $X, Y$} & \multicolumn{3}{|c|}{ Weighted 4-NN X,Y } \\
\hline & $\begin{array}{l}\text { Basic } \\
\text { finger } \\
\text { print }\end{array}$ & $\begin{array}{l}\text { Linear } \\
\text { taper }\end{array}$ & $\begin{array}{l}\text { Expo. } \\
\text { taper }\end{array}$ & $\begin{array}{l}\text { Basic } \\
\text { finger } \\
\text { print }\end{array}$ & $\begin{array}{l}\text { Linear } \\
\text { taper }\end{array}$ & $\begin{array}{l}\text { Expo. } \\
\text { taper }\end{array}$ & $\begin{array}{l}\text { Basic } \\
\text { finger } \\
\text { print }\end{array}$ & $\begin{array}{l}\text { Linear } \\
\text { taper }\end{array}$ & $\begin{array}{l}\text { Expo. } \\
\text { taper }\end{array}$ & $\begin{array}{l}\text { Basic } \\
\text { finger } \\
\text { print }\end{array}$ & $\begin{array}{l}\text { linear } \\
\text { taper }\end{array}$ & $\begin{array}{l}\text { Expo. } \\
\text { taper }\end{array}$ & $\begin{array}{l}\text { Basic } \\
\text { finger } \\
\text { print }\end{array}$ & $\begin{array}{l}\text { Linear } \\
\text { taper }\end{array}$ & $\begin{array}{l}\text { Expo. } \\
\text { taper }\end{array}$ \\
\hline 22 & 13 & $0 \quad 3.8$ & 0.91 .3 & 03 & $0.3 \quad 3.5$ & 1.21 .4 & 12 & $0.3 \quad 3.7$ & 1.00 .9 & 04 & $0.4 \quad 4.1$ & 1.30 .9 & 0.92 .9 & $0.5 \quad 3.6$ & 0.91 .3 \\
\hline 23 & 14 & $\begin{array}{lll}0 & 5.5\end{array}$ & 1.21 .3 & 15 & 0.24 .5 & 0.81 .4 & 03 & $0 \quad 4.7$ & $1.3 \quad 1.2$ & 04 & $0.1 \quad 5.2$ & 1.21 .5 & 0.54 .5 & 0.24 .5 & 1.41 .6 \\
\hline 35 & 24 & 1.18 .0 & 2.23 .5 & 23 & 1.37 .6 & $1.8 \quad 3.7$ & 26 & 1.27 .1 & 1.74 .1 & 23 & 0.99 .0 & $2.6 \quad 2.7$ & 2.13 .3 & 1.48 .6 & 2.12 .8 \\
\hline 44 & 012 & $5.8 \quad 3.2$ & 4.52 .4 & 48 & $\begin{array}{ll}5.2 & 2.4\end{array}$ & $\begin{array}{ll}5.3 & 2.4\end{array}$ & 79 & $\begin{array}{ll}5.4 \quad 2.4 \\
\end{array}$ & 6.43 .1 & 67 & $\begin{array}{lll}5.3 & 1.6\end{array}$ & $\begin{array}{ll}3.2 & 2.2\end{array}$ & 5.87 .31 & $\begin{array}{ll}5.82 .0 \\
\end{array}$ & 5.33 .2 \\
\hline $\begin{array}{ll}0 & 8\end{array}$ & 412 & 2.410 & 1.78 .6 & 46 & 2.49 .8 & $\begin{array}{ll}1.3 \quad 9.6\end{array}$ & 55 & 2.49 .2 & $\begin{array}{ll}1.6 & 9.3\end{array}$ & 47 & 1.49 .8 & 1.410 .0 & 4.147 .5 & 2.59 & $\begin{array}{ll}1.7 & 9.1\end{array}$ \\
\hline 88 & 812 & 86.4 & 7.16 .7 & 812 & \begin{tabular}{ll|}
8 & 6.6
\end{tabular} & 6.56 .6 & 89 & 7.26 .4 & 6.66 .8 & 99 & 7.27 .1 & 6.86 .7 & 9.89 .2 & 7.27 .4 & 7.36 .2 \\
\hline 128 & 1212 & 116.6 & 117.1 & 1210 & $10.5 \quad 6.5$ & 10.76 .9 & 1111 & $\begin{array}{l}0.4 \quad 7.1 \\
\end{array}$ & 10.46 .7 & $10 \mathrm{~s}$ & $\begin{array}{ll}10.5 \quad 6.7\end{array}$ & 11.26 .9 & 10.38 .5 & 10.66 .8 & 10.46 .7 \\
\hline $\begin{array}{ll}4 \quad 12 \\
\end{array}$ & 88 & 5.6 & 4.810 .8 & 612 & $\begin{array}{ll}4.6 & 13.2\end{array}$ & $\begin{array}{lll}5.5 & 10.7\end{array}$ & 511 & $\begin{array}{ll}4.8 & 13.2\end{array}$ & 5.413 .4 & 611 & $\begin{array}{lll}5.6 & 13.2\end{array}$ & $\begin{array}{lll}5.611 .6 \\
\end{array}$ & 6.3610 .2 & 5.613 .6 & $\begin{array}{l}4.6 \quad 13.7 \\
\end{array}$ \\
\hline 812 & 88 & 6.414 & 7.110 .6 & 68 & $7.4 \quad 13$ & $\begin{array}{ll}0.8 & 10.7\end{array}$ & 511 & \begin{tabular}{ll|}
6.5 & 13.6
\end{tabular} & $\begin{array}{l}6.510 .8 \\
\end{array}$ & 511 & \begin{tabular}{ll|}
6.2 & 14
\end{tabular} & $\begin{array}{lll}6.210 .8 \\
\end{array}$ & $\begin{array}{lll}7.01 & 8.8\end{array}$ & $\begin{array}{ll}6.613 .8 \\
\end{array}$ & $\begin{array}{l}6.413 .8 \\
\end{array}$ \\
\hline 416 & 812 & 5.414 .4 & 5.014 .7 & 810 & $\begin{array}{lll}5.6 & 17.6\end{array}$ & 4.714 .7 & 812 & 5.718 & 5.517 .3 & 713 & 4.416 .6 & 5.114 .6 & 7.4312 .3 & $\begin{array}{ll}5.3 & 17\end{array}$ & 5.714 .0 \\
\hline
\end{tabular}

\subsection{Hybrid Exponential Interpolation}

RF signal amplitudes decrease with the distance as they reach to receivers from transmitters. Generally, this decrease is in exponential form. Initially,wireless sensor receivers are placed in front of wireless sensortransmitters. The distance between them is increased in steps of 1 metre 
and RF signal amplitude recordingsby the receiver in the form of LQI values are plotted against distance.A best fit curve reveals an exponential distribution function of $a e^{-b x}$ as seen in Figure 10.

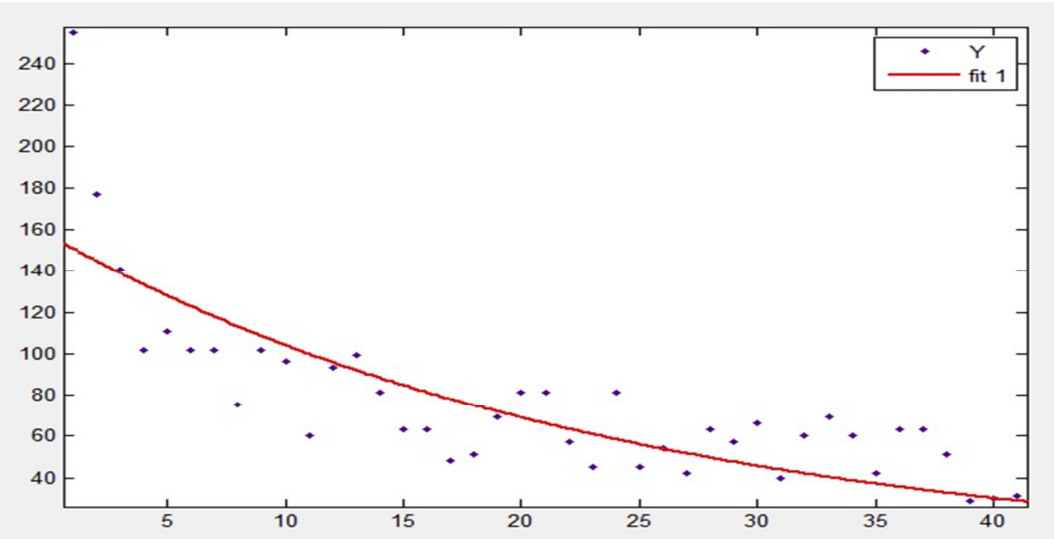

Figure 10. Plot of LQI values versus distance between a receiver and a transmitter with a best fit curve

In order to reflect this characteristic in the virtual world, Virtual Fingerprint map is generated by using exponential taper function between every 2 adjacent grid points. Initially, LQI values are recorded at each grid point. Exponential Taper functions are applied in $\mathbf{x a n d} \mathbf{y}$ directions of the grid cell asseen in Figure 6 and 7.LQI amplitude at every virtual grid point is calculated with the assistance of exponential taper functions.k-NN andweighted k-NN localization algorithms are employed to calculate the unknown object coordinates with the virtual database generated usingExponential taper function. The results are presented in Table6.The location estimation error, $\mathrm{e}$, is defined by the linear distance between the unknown object coordinates $\left(\mathrm{x}_{\mathrm{t}}, \mathrm{y}_{\mathrm{t}}\right)$ and their estimated coordinates $\left(\mathrm{x}_{\mathrm{e}}, \mathrm{y}_{\mathrm{e}}\right)$. It is given by:

$e=\sqrt{\left(x_{e}-x_{t}\right)^{2}+\left(y_{e}-y_{t}\right)^{2}}$

Error calculation results between the actual and the estimated object coordinates by using basic fingerprint database and the virtual fingerprint databases are tabulated in Table 7. It can be concluded that the best localization results are achieved with exponential taper function.

\section{Conclusions}

Virtual localization approach is a novel and time effective indoor localization technique. The proposed positioning system uses a number of transmitters and a receiver as in basic fingerprint systems. The originality lies in the introduction of virtual grid points with specific LQI taper functions among the physical grid points.

Previously, fingerprint mapping techniques are utilized to obtain localization accuracies of around 1 grid space.To increase the accuracies, number of fingerprint points are increased across the sensing area and the localization accuracies of slightly less that a grid space are achieved. This improved the accuracies but also increased the effort to build a fingerprint map. The key idea of the proposed approach is to obtain a more accurate object localization by keeping the same fingerprint map but increase the number of grid points. Each grid point is an LQI measurement point and the recordings of LQI values at these points are utilized to estimate the object location. A solution to increase the positioning accuracy is to put more grid points which will be more labour intensive and time consuming. The idea behind the proposed 
approach is to simulate a larger number of grid pointsby introducing virtual grid points and keeping the samenumber of real grid points.

Table 7. Overall error calculations for 3 fingerprint database systems.

\begin{tabular}{|c|c|c|c|c|c|c|}
\hline $\begin{array}{l}\text { Unknown } \\
\text { positions }\end{array}$ & $\begin{array}{c}\text { Error calcula } \\
\text { virtual fingerp }\end{array}$ & $\begin{array}{l}\text { ns betw } \\
\text { t datab }\end{array}$ & $\begin{array}{l}\text { n target and averag } \\
\text { s (linear and hybri }\end{array}$ & $\begin{array}{l}\text { stimate } \\
\text { expone }\end{array}$ & $\begin{array}{l}\text { positions using be } \\
\text { al interpolation } f\end{array}$ & $\begin{array}{l}\text { ic and } \\
\text { ictions) }\end{array}$ \\
\hline $\mathbf{X} \mathbf{Y}$ & $\begin{array}{c}\text { Basic } \\
\text { fingerprint } \\
\text { ave }\end{array}$ & $\begin{array}{c}\text { Error } \\
(\mathbf{m})\end{array}$ & $\begin{array}{l}\text { Virtual Fingerprint } \\
\text { Ave (linear taper) }\end{array}$ & $\begin{array}{c}\text { Error } \\
(\mathrm{m})\end{array}$ & $\begin{array}{c}\text { Virtual } \\
\text { Fingerprint Ave } \\
\text { (exp. taper) }\end{array}$ & $\begin{array}{c}\text { Error } \\
(\mathbf{m})\end{array}$ \\
\hline 2 & $\begin{array}{ll}0.5 & 3 \\
\end{array}$ & 1.8 & $\begin{array}{|ll|}0.3 & 3.8 \\
\end{array}$ & 2.5 & $\begin{array}{ll}1.0 & 1.2 \\
\end{array}$ & 1.3 \\
\hline 3 & $0.5 \quad 4.1$ & 1.9 & 0.14 .9 & 2.7 & $1.2 \quad 1.4$ & 1.8 \\
\hline 5 & $1.5 \quad 2.8$ & 2.7 & 1.28 .0 & 3.5 & $2.0 \quad 3.3$ & 2.0 \\
\hline 4 & 4.5 & 4.6 & $5.5 \quad 2.3$ & 2.3 & $4.9 \quad 2.6$ & 1.6 \\
\hline 8 & $4.2 \quad 7.5$ & 4.2 & $2.2 \quad 12.1$ & 4.7 & 1.5 & 1.5 \\
\hline 8 & $8.5 \quad 10.2$ & 2.2 & $7.5 \quad 6.8$ & 1.3 & 6.8 & 1.8 \\
\hline 128 & $11.1 \quad 9.9$ & 2.0 & $10.6 \quad 6.8$ & 1.8 & $10.7 \quad 6.8$ & 1.8 \\
\hline $\begin{array}{ll}4 & 12 \\
\end{array}$ & $\begin{array}{ll}6.3 & 10.4 \\
\end{array}$ & 2.8 & $\begin{array}{ll}5.2 & 13.1 \\
\end{array}$ & 1.6 & \begin{tabular}{|ll}
5.3 & 12.2 \\
\end{tabular} & 1.3 \\
\hline 12 & 9.4 & 3.1 & $\begin{array}{ll}6.6 & 13.6 \\
\end{array}$ & 2.1 & $\begin{array}{ll}6.5 & 11.3 \\
\end{array}$ & 1.7 \\
\hline 16 & $\begin{array}{ll}7.6 & 11.8 \\
\end{array}$ & 5.5 & $\begin{array}{ll}5.2 & 16.7 \\
\end{array}$ & 1.4 & $\begin{array}{ll}5.6 & 15.0 \\
\end{array}$ & 1.9 \\
\hline \multicolumn{2}{|c|}{ Total Avg. error(m) } & 3.1 & & 2.4 & & 1.7 \\
\hline
\end{tabular}

The proposed system has the following advantages. Firstly, the hardware cost is the same as fingerprint localization systems. Secondly, the number of measurement points corresponding to grid points in the test area is unchanged and only extra virtual grid points are introduced between these grid points. Hence less time and effort is spent during off line phase. Both real and virtual grid points are used together to generate a new fingerprint database for location determination.

The shortcomings of the virtual grids are their numbers across the sensing area. In theory, higher the density of grid points, greater the localization accuaracy. Although there is no extra cost of having more virtual grid points, maximum number of virtual grid points is limited with respect to localization accuracies. There is a trade off between the localization accuracies and the number of real and virtual grid points. Optimum localization accuriess are obtained with $\mathrm{n}=5$. Hence, 4 virtual grid points are utilized between two adjacent real grid points by dividing the distance into $n=5$ equal sections between them. Any other number of virtual grid points betweentwo adjacent grid points reduced the positioning accuracies with both taper functions. In the study, total number of grid points is 416 across the test area with 24 of them are real and 392 of them are virtual. If the number of virtual grid points are increased more than 392 with $\mathrm{n}>5$, there is a deterioration observed in localization accuracies. Any virtual grid number less than 392 with $\mathrm{n}<5$, alsocauses a degration in localization accuracies. Consequently in our approach an optimum of 15 grid cells each with 25 virtual grid cells are employed across the sensing area by using $n=5$.

Once the total grid space is determined, LQI values at physical grid points are interpolated among the virtual grids corresponding to predefined taper functions. In fingerprint localization systems, fingerprint database is compared with unknown fingerprint signatures of the objects.

Basic fingerprint approach has an average localization error of $3.1 \mathrm{~m}$ while Linear interpolation technique has an average localization error of $2.4 \mathrm{~m}$ where LQI values are linearly distributed between the virtual grid points. Hybrid exponential interpolationtechnique, on the other hand, has an average error of $1.7 \mathrm{~m}$. LQI distribution between the grid points simulates the propagation characteristicsof LQI values against distance.Exponential approach gives the minimum distance error among 3 techniques. 
In this study, position detection is implemented in a confined area of a sports hall. But the same technique can also be generalized in any indoor area. The main idea was to see the applicability of virtual fingerprint technique in any test area. In second stage, other indoor areas will also be tested with this newtechnique. Environmental conditions affect the LQI reception by the receivers. If there are more obstacles in the sensing area,localization accuracies are decreased accordingly, To reduce these affects, signal averaging and outlier techniques are employed on the recorded LQIvalues. Based on the observations of the complex relationship between LQI values and the distances between transmitters and receivers, Non linear interpolation algorithms can improve localization accuraciesin large indoor areas. Hybrid exponentialinterpolation algorithm is one of these algorithms whichcan compensate the nonlinear behaviour of RF signals and in return generates better localization accuracies.

\section{REFERENCES}

[1] Lionel M. NI and Yunhao, Liu Yiu Cho Lau and Abhishek Patil ; LANDMARC: Indoor Location Sensing Using Active RFID Wireless Networks 10, 701-710, 2004

[2] R.Want, A.Hopper,V.Falcao and J.Gibbons; The activeBadgelocationsystem,ACM Transactions on Information systems Vol. 40, No. 1, pp. 91-102, January 1992

[3] R.Want, B.Schilit, N. Adams, R. Gold, D. Gold- berg, K.Petersen ,J.Ellis, M Weiser; The Parctab Ubiquitous Computing Experiment", Book Chapter: "Mobile Computing”, Kluwer Publishing, Edited by Tomasz Imielinski, Chapter 2, pp 45-101, ISBN 0-7923-9697-9, February 1997.

[4] A.Ward, A.Jones, A.Hopper: A neq location technique for the active office, In IEEE personal Communication Magazine, Volume 4 no 5,pages 42-47, October 1997

[5] A.Harter ,A.Hopper, P.Steggles, A.Ward, P. Webster; The anatomy of a context aware application, In proceedings of the 5th annual ACM/IEEE international conference on Mobile Computing and Networking,pages 59-68,August 1999

[6] P. Bahl, V.N. Padmanabhan; RADAR: An in-building RF-based user location and tracking system, in: Proceedings of IEEE INFOCOM 2000, Tel-Aviv, Israel (March 2000),

[7] J. Hightower, R. Want and G. Borriello; SpotON: An indoor 3D location sensing technology based on RFsignalstrength, UW CSE00-02-02, February 2000,

[8] Konrad Lorincz, Matt Welsh ; MoteTrack: A Robust, Decentralized Approach to RF-Based Location Tracking, Proceedings of the International Workshop on Location and Con13RadioFrequencyIdentification (RFID) home page,

[9] Junhuai Li,Rui Qi,Yile Wang,Feng Wang; An RFID location Model based On Virtual reference tag spacemJournal of Computational Information systems 7:6 ,pp 2014-2111,2011

[10] Yiyang Zhao,Yunhao Liu,Lionel Ni ; Vire, Active RFID based Localization Using Virtual Reference Elimination,Int conference on paralel processing ,pp 56-63, 2007

[11] Kamol Kaemarungsi,prashant krishnamurthy " modelling of indoor positioning systems based on location fingerprinting”, ,IEEE info com 2004, 0-7803-8356-7

[12] Guang-yao Jin, Xiao-yi Lu,Myong Soon Park," An indoor localization mechanism using active RFID tag",proceedings of IEEE conference on sensor networks SUTC ,2006, 0-7695-2553-9

[13] Jan Blumenthal, Ralf grossmann, Frank Gola- towski "weighted centroid localization in zigbeebased sensor networks", CELISCA center for life science automation,2007

[14] http://www.jennic.com/jennic_support/application_notes/jn-an-1052_home_sensor_demons tration_using_zigbee

[15] http://www.jennic.com/support/solutions/00004 
International Journal of Wireless \& Mobile Networks (IJWMN) Vol. 5, No. 6, December 2013

\section{Authors}

Hakan Koyuncu is a PHD research student in computer science department of Loughborough University. He has received his Bsc in Computer Engineering from Turkey and Msc in Computer Science from Loughborough University. He is working on wireless sensor networks and RFID devices. His current research is on position detection of objects indoors. He has published several papers on the subject.

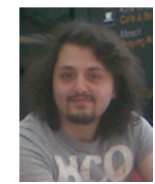

Professor Shuang-Hua Yang received his BSc and MSc from Petroleum University in 1983 and 1986, and PhD from Zhejiang University in 1991. He moved to England in 1995 and joined Loughborough in 1997 first as research assistant, university research fellow, then became lecturer in 2000 and senior lecturer in 2003. He was promoted to professor in 2006.

As a principal investigator he has received a number of significant research grants from

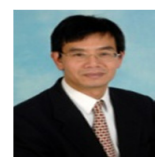
different funding bodies, including EPSRC, Royal Society, TSB, MoD, EU, Royal Academy of Engineering, British Council, London Mathematic Society, and some overseas funding organisations. Over 130 academic research papers on quality international journals and conferences have been resulted from his research. He was one of the pioneer investigators in the UK working on Internet-based control in the UK and published one monograph on the topic in 2011 by Springer, London. His work has been widely cited by the following-up researchers. He is a wireless sensor network (WSN) specialist and has completed a number of large-scale research projects in the area, among which SafetyNET system (www.firesafetyNET.org.uk) and IndeedNET system (www.indeednet.org) have been commercialised. His latest monograph is titled as WSN - Principle, Design and Applications, published by Springer. He lectures WSN and wireless communication in the department. 